\title{
Physicochemical Study of some imidazoline derivatives in solutions
}

\author{
Shipra Baluja, Nikunj Kacchadia \\ Department of Chemistry, Saurashtra University \\ Rajkot- 360 005, Gujarat (INDIA) \\ E-mail address: shipra_baluja@rediffmail.com
}

Keywords: Imidazoline derivative, Conductance, Refractive Index, Density,

ABSTRACT. Some physicochemical properties such as density, refractive index, conductance etc. have been studied for some newly synthesized imidazoline derivatives in different solvents at $308.15 \mathrm{~K}$.

\section{INTRODUCTION}

The synthesis of imidazoline derivatives continues to attract much interest in organic chemistry due to its various therapeutic properties [1-8]. This class of compounds is known to have applications in various fields [9, 10]. Analogs containing imidazoline are also found in antihistaminic However, best of our knowledge, very little work is known for their physicochemical properties.

Thus, the present work was undertaken to study some physicochemical properties such as density, refractive index and conductance of synthesized imidazoline derivatives in solutions.

\section{EXPERIMENTAL}

Overall, ten different imidazoline derivatives have been synthesized and their general structure is given in Figure 1. The structures of all the synthesized compounds were confirmed by IR, ${ }^{1} \mathrm{H}$ NMR and mass spectral data. Table 1 shows the physical parameters of synthesized imidazoline compounds.

Physicochemical studies: The solvents dimethylformamide (DMF) and dimethyl sulfoxide (DMSO) were used for the physicochemical studies. All these solvents were purified by standard methods ${ }^{11}$.

Density and refractive index: The density and refractive index of all the synthesized imidazoline derivatives have determined in dimethylformamide and dimethyl sulfoxide solutions at $308.15 \mathrm{~K}$. The density and refractive index were measured at definite temperature by pyknometer and Abbe refractometer respectively. The temperature was maintained by circulating water through jacket around the prisms of refractometer from an electronically controlled water bath (NOVA NV-8550 E). The uncertainty of temperature was $\pm 0.1{ }^{0} \mathrm{C}$ and that of density and refractive index was \pm $0.0001 \mathrm{~g} / \mathrm{cm}^{3}$ and 0.0005 respectively.

Conductance: For all the synthesized compounds, conductance is measured in dimethylformamide and dimethylsulfoxide solutions at $308.15 \mathrm{~K}$. The conductance of each solution was measured by using Equip-tronics conductivity meter (Model No. 664) having a cell constant $0.85 \mathrm{~cm}^{-1}$ at 308.15 K.

\section{RESULTS AND DISCUSSION:}

The molecular formula, molecular weight, melting point, \% yield and $\mathrm{R}_{\mathrm{f}}$ values along with the solvent systems of all the compounds are given in Table 1.

\section{Density and Refractiove index:}

The density of solution is related to density of pure solvent, pure solute (i.e., synthesized compound) and their weight fractions by the following equation:

$$
1 / \rho_{12}=g_{1} / \rho_{1}+g_{2} / \rho_{2}
$$


where $\rho_{1}, \rho_{2}$ and $\rho_{12}$ are the density of pure solvent, pure solute (i.e., synthesized compound) and solution respectively. $g_{1}$ and $g_{2}$ are the weight fractions of solvent and solute respectively. The slope of the plot of $1 / \mathrm{g}_{1} \rho_{12}$ versus $\mathrm{g}_{1} / \mathrm{g}_{2}$ gives $1 / \rho_{2}$. equation $^{(12)}$.

Further, the density of these compounds was also calculated using the following theoretical

$$
\rho=\mathrm{KM} / \mathrm{N}_{\mathrm{A}} \sum \Delta \mathrm{V}_{\mathrm{i}}
$$

where $\rho$ the density of the compound, $\mathrm{K}$ is packing fraction (0.599), $\mathrm{M}$ is the molecular weight of the compound, $\mathrm{N}_{\mathrm{A}}$ is the Avogadro's number and $\Delta \mathrm{V}_{\mathrm{i}}$ is the volume increment of the atoms and atomic groups present in the compound. Table 2 shows the experimental and theoretical values of density. It is observed that there is deviation between experimental and theoretical density values and in different solvents, different density values are observed. This difference can be explained on the basis of interactions in solutions. In different solvents, different types of interactions exist with different solutes. This may change the volume thereby affecting the molecular weight of the compound, which ultimately affects the density. Thus, different density values in different solvents and deviation between experimental and theoretical density values suggest the presence of intermolecular interactions between solute and solvent molecules.

The molar refraction of pure liquid and solutions can be determined according to Lorentz and Lorentz equations ${ }^{13}$.

For pure liquid:

$$
(\mathrm{MRD})=\left[\left(\mathrm{n}^{2}-1\right) /\left(\mathrm{n}^{2}+2\right)\right] \cdot \mathrm{M} / \mathrm{\rho}
$$

where $n, M$ and $\rho$ are refractive index, molecular weight and density of pure liquid respectively. For solutions:

$$
(\mathrm{MRD})_{12}=\left[\left(\mathrm{n}^{2}{ }_{12}-1\right) /\left(\mathrm{n}^{2}{ }_{12}+2\right)\right] \cdot\left(\mathrm{X}_{1} \mathrm{M}_{1}+\mathrm{X}_{2} \mathrm{M}_{2}\right) / \rho_{12}
$$

where $n_{12}$ and $\rho_{12}$ are refractive index and density of the solution respectively. $X_{1}$ and $X_{2}$ are the mole fractions and $\mathrm{M}_{1}$ and $\mathrm{M}_{2}$ are the molecular weight of the solvent and solute respectively.

Using these equations, the (MRD) 2 and refractive index of compounds in $0.1 \mathrm{M}$ solutions were calculated and are given in Table 3. It is observed that both (MRD) 2 and refractive index of compounds are different in each solvent. This again proves that in different solvents, intermolecular interactions are different which affects these parameters. In some solvents, aggregation or hydrogen bonding takes place whereas in others, breakage of bonds takes place. As refractive index and molar refraction depends not only upon atomic refraction but also on single, double or triple bonds, these

\begin{tabular}{|c|c|c|c|c|c|c|c|}
\hline $\begin{array}{l}\text { Sr. } \\
\text { No. }\end{array}$ & Comp. Code & $\begin{array}{l}\text { Mol.Wt. } \\
\text { (g) }\end{array}$ & M.F. & $\mathrm{R}$ & $\begin{array}{c}\mathrm{R}_{\mathrm{f}}^{*} \\
\text { Value }\end{array}$ & $\begin{array}{c}\text { M.P. } \\
{ }^{\circ} \mathrm{C}\end{array}$ & $\begin{array}{c}\text { Yield } \\
\%\end{array}$ \\
\hline 1. & IM-1 & 525 & $\mathrm{C}_{32} \mathrm{H}_{23} \mathrm{O}_{3} \mathrm{~N}_{5}$ & $4-\mathrm{OCH}_{3}-\mathrm{C}_{6} \mathrm{H}_{4}-$ & 0.48 & 215 & 69 \\
\hline 2. & IM -2 & 541 & $\mathrm{C}_{32} \mathrm{H}_{23} \mathrm{O}_{4} \mathrm{~N}_{5}$ & $4-\mathrm{CH}_{3}-\mathrm{C}_{6} \mathrm{H}_{4-}$ & 0.51 & 205 & 72 \\
\hline 3. & IM -3 & 525 & $\mathrm{C}_{32} \mathrm{H}_{23} \mathrm{O}_{3} \mathrm{~N}_{5}$ & $2-\mathrm{OCH}_{3}-\mathrm{C}_{6} \mathrm{H}_{4}-$ & 0.42 & 226 & 65 \\
\hline 4. & IM -4 & 564 & $\mathrm{C}_{35} \mathrm{H}_{25} \mathrm{O}_{3} \mathrm{~N}_{5}$ & $\mathrm{C}_{10} \mathrm{H}_{7^{-}}$ & 0.47 & 232 & 67 \\
\hline 5. & IM -5 & 529 & $\mathrm{C}_{31} \mathrm{H}_{20} \mathrm{O}_{3} \mathrm{~N}_{5} \mathrm{~F}$ & $4-\mathrm{F}-\mathrm{C}_{6} \mathrm{H}_{4-}$ & 0.42 & 198 & 62 \\
\hline 6. & IM -6 & 546 & $\mathrm{C}_{31} \mathrm{H}_{20} \mathrm{O}_{3} \mathrm{~N}_{5} \mathrm{Cl}$ & 4-Cl- $\mathrm{C}_{6} \mathrm{H}_{4-}$ & 0.43 & 203 & 65 \\
\hline 7 & IM -7 & 511 & $\mathrm{C}_{31} \mathrm{H}_{21} \mathrm{O}_{3} \mathrm{~N}_{5}$ & $\mathrm{C}_{6} \mathrm{H}_{5^{-}}$ & 0.33 & 189 & 66 \\
\hline 8. & IM -8 & 564 & $\mathrm{C}_{31} \mathrm{H}_{19} \mathrm{O}_{3} \mathrm{~N}_{5} \mathrm{FCl}$ & $3-\mathrm{Cl}-4-\mathrm{F}-\mathrm{C}_{6} \mathrm{H}_{4}-$ & 0.32 & 211 & 68 \\
\hline 9. & IM -9 & 580 & $\mathrm{C}_{31} \mathrm{H}_{19} \mathrm{O}_{3} \mathrm{~N}_{5} \mathrm{Cl}_{2}$ & $2,5-\mathrm{di}-\mathrm{Cl}-\mathrm{C}_{6} \mathrm{H}_{4}-$ & 0.57 & 212 & 69 \\
\hline
\end{tabular}
parameters are affected by the type of interactions taking place in solution.

Table 1: Physical constants of synthesized imidazoline derivatives

*Acetone : benzene: 1:9 
Table 2: Experimental and calculated densities of compounds in DMF and DMSO solutions at $298.15 \mathrm{~K}$.

\begin{tabular}{|c|c|c|c|}
\hline \multirow{2}{*}{ Compounds } & \multicolumn{2}{|c|}{ Experimental Density gm $/ \mathrm{cm}^{3}$} & $\begin{array}{c}\text { Theoretical } \\
\text { Density gm } / \mathrm{cm}^{3}\end{array}$ \\
\cline { 2 - 3 } & DMF & DMSO & 1.2018 \\
\hline IM-1 & 1.2513 & 1.1637 & 1.2170 \\
\hline IM -2 & 1.1444 & 1.1660 & 1.2018 \\
\hline IM -3 & 1.1275 & 1.1596 & 1.1849 \\
\hline IM -4 & 1.1673 & 1.1786 & 1.2472 \\
\hline IM -5 & 1.2285 & 1.1410 & 1.2578 \\
\hline IM -6 & 1.2794 & 1.1827 & 1.1952 \\
\hline IM -7 & 1.2226 & 1.1801 & 1.2559 \\
\hline IM -8 & 1.1174 & 1.1700 & 1.2667 \\
\hline IM -9 & 1.1853 & 1.1680 & \\
\hline
\end{tabular}

Table 3: Calculated molar refraction and refractive index of $0.1 \mathrm{M}$ solution of compounds in DMF and DMSO at $298.15 \mathrm{~K}$.

\begin{tabular}{|c|c|c|c|c|}
\hline \multirow{2}{*}{ Compounds } & \multicolumn{4}{|c|}{ Solvents } \\
\cline { 2 - 5 } & \multicolumn{2}{|c|}{ DMF } & \multicolumn{2}{c|}{ DMSO } \\
\cline { 2 - 5 } & $(\mathrm{MRD})_{2}$ & $\mathrm{n}$ & $(\mathrm{MRD})_{2}$ & $\mathrm{n}$ \\
\hline IM-1 & 156.00 & 1.6660 & 166.50 & 1.6598 \\
\hline IM -2 & 183.75 & 1.7042 & 172.00 & 1.6626 \\
\hline IM -3 & 151.50 & 1.5643 & 164.00 & 1.6443 \\
\hline IM -4 & 164.50 & 1.5970 & 184.00 & 1.6960 \\
\hline IM -5 & 142.00 & 1.5728 & 169.00 & 1.6487 \\
\hline IM -6 & 181.00 & 1.7914 & 175.50 & 1.6862 \\
\hline IM -7 & 145.50 & 1.6122 & 167.00 & 1.6972 \\
\hline IM -8 & 166.25 & 1.5729 & 191.50 & 1.7256 \\
\hline IM -9 & 184.50 & 1.6774 & 183.50 & 1.6603 \\
\hline
\end{tabular}

Table 4: The measured conductance ( $\kappa)$ of synthesized compounds in DMF at 298.15 K.

\begin{tabular}{|c|c|c|c|c|c|c|c|c|c|}
\hline Conc.(M) & \multicolumn{9}{|c|}{ к.10 (mho) } \\
\hline & IM-1 & IM-2 & IM-3 & IM-4 & IM-5 & IM-6 & IM-7 & IM-8 & IM-9 \\
\hline 0.000 & 4.6 & 4.6 & 4.6 & 4.6 & 4.6 & 4.6 & 4.6 & 4.6 & 4.6 \\
\hline 0.001 & 5.3 & 5.2 & 5.4 & 5.2 & 5.0 & 5.4 & 5.3 & 5.5 & 5.3 \\
\hline 0.002 & 5.9 & 5.6 & 5.8 & 5.6 & 5.2 & 6.0 & 5.7 & 6.1 & 5.5 \\
\hline 0.004 & 6.6 & 6.1 & 6.4 & 6.1 & 5.4 & 7.0 & 6.4 & 7.0 & 5.8 \\
\hline 0.006 & 8.1 & 6.6 & 7.0 & 6.7 & 5.6 & 7.8 & 7.0 & 7.7 & 6.1 \\
\hline 0.008 & 9.2 & 7.0 & 7.6 & 7.3 & 5.8 & 8.5 & 7.6 & 8.2 & 6.4 \\
\hline 0.010 & 9.9 & 7.5 & 8.0 & 7.6 & 6.1 & 9.2 & 8.2 & 8.6 & 6.8 \\
\hline 0.020 & 11.1 & 9.5 & 9.9 & 9.9 & 7.1 & 12.6 & 10.4 & 11.2 & 7.6 \\
\hline 0.040 & 13.9 & 13.5 & 13.2 & 14.5 & 8.9 & 17.5 & 14.5 & 16.3 & 8.2 \\
\hline 0.060 & 16.5 & 17.0 & 16.3 & 18.7 & 10.4 & 22.5 & 18.2 & 20.8 & 9.2 \\
\hline 0.080 & 19.7 & 20.0 & 19.2 & 21.9 & 11.6 & 26.1 & 21.8 & 24.7 & 10.5 \\
\hline 0.100 & 25.7 & 23.0 & 21.7 & 25.0 & 13.1 & 29.3 & 25.4 & 28.4 & 11.6 \\
\hline
\end{tabular}


Table 5: The measured conductance $(\kappa)$ of synthesized compounds in DMSO at 298.15K.

\begin{tabular}{|c|c|c|c|c|c|c|c|c|c|}
\hline Conc.(M) & \multicolumn{10}{|c|}{ K. $\mathbf{5}^{\mathbf{5}}$ (mho) } \\
\hline & IM-1 & IM-2 & IM-3 & IM-4 & IM-5 & IM-6 & IM-7 & IM-8 & IM-9 \\
\hline 0.000 & 0.4 & 0.4 & 0.4 & 0.4 & 0.4 & 0.4 & 0.4 & 0.4 & 0.4 \\
\hline 0.001 & 0.5 & 0.6 & 0.6 & 0.5 & 0.5 & 0.7 & 0.6 & 0.9 & 0.5 \\
\hline 0.002 & 0.6 & 0.9 & 0.9 & 0.6 & 0.6 & 1.0 & 0.8 & 1.3 & 1.0 \\
\hline 0.004 & 0.8 & 1.3 & 1.5 & 0.8 & 0.8 & 1.5 & 1.2 & 2.1 & 1.7 \\
\hline 0.006 & 1.0 & 1.7 & 2.0 & 1.1 & 1.0 & 2.1 & 1.5 & 2.7 & 2.7 \\
\hline 0.008 & 1.2 & 2.1 & 2.4 & 1.8 & 1.1 & 2.4 & 1.8 & 3.4 & 4.1 \\
\hline 0.010 & 1.4 & 2.5 & 2.8 & 2.0 & 1.3 & 3.1 & 2.1 & 4.0 & 6.8 \\
\hline 0.020 & 2.3 & 4.3 & 5.0 & 3.5 & 2.3 & 5.3 & 3.5 & 6.8 & 9.6 \\
\hline 0.040 & 3.9 & 7.4 & 8.6 & 6.3 & 3.9 & 9.4 & 6.1 & 10.8 & 10.1 \\
\hline 0.060 & 5.6 & 10.5 & 12.4 & 8.8 & 5.3 & 12.8 & 8.7 & 15.0 & 11.8 \\
\hline 0.080 & 7.2 & 13.1 & 14.7 & 11.2 & 7.1 & 15.8 & 10.9 & 18.5 & 14.0 \\
\hline 0.100 & 8.8 & 15.3 & 17.9 & 13.4 & 8.2 & 20.3 & 12.9 & 21.3 & 16.6 \\
\hline
\end{tabular}

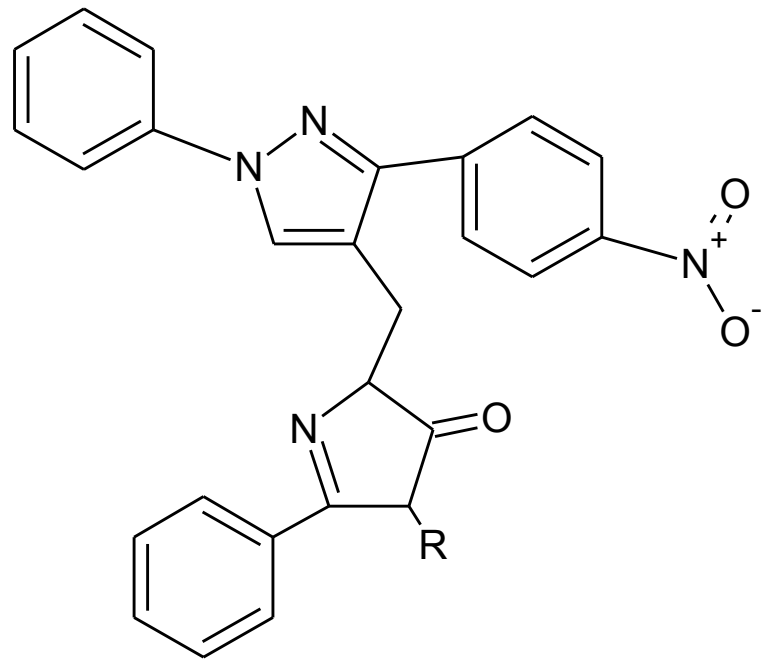

Figure 1: General structure of imidazoline derivatives 
[A]

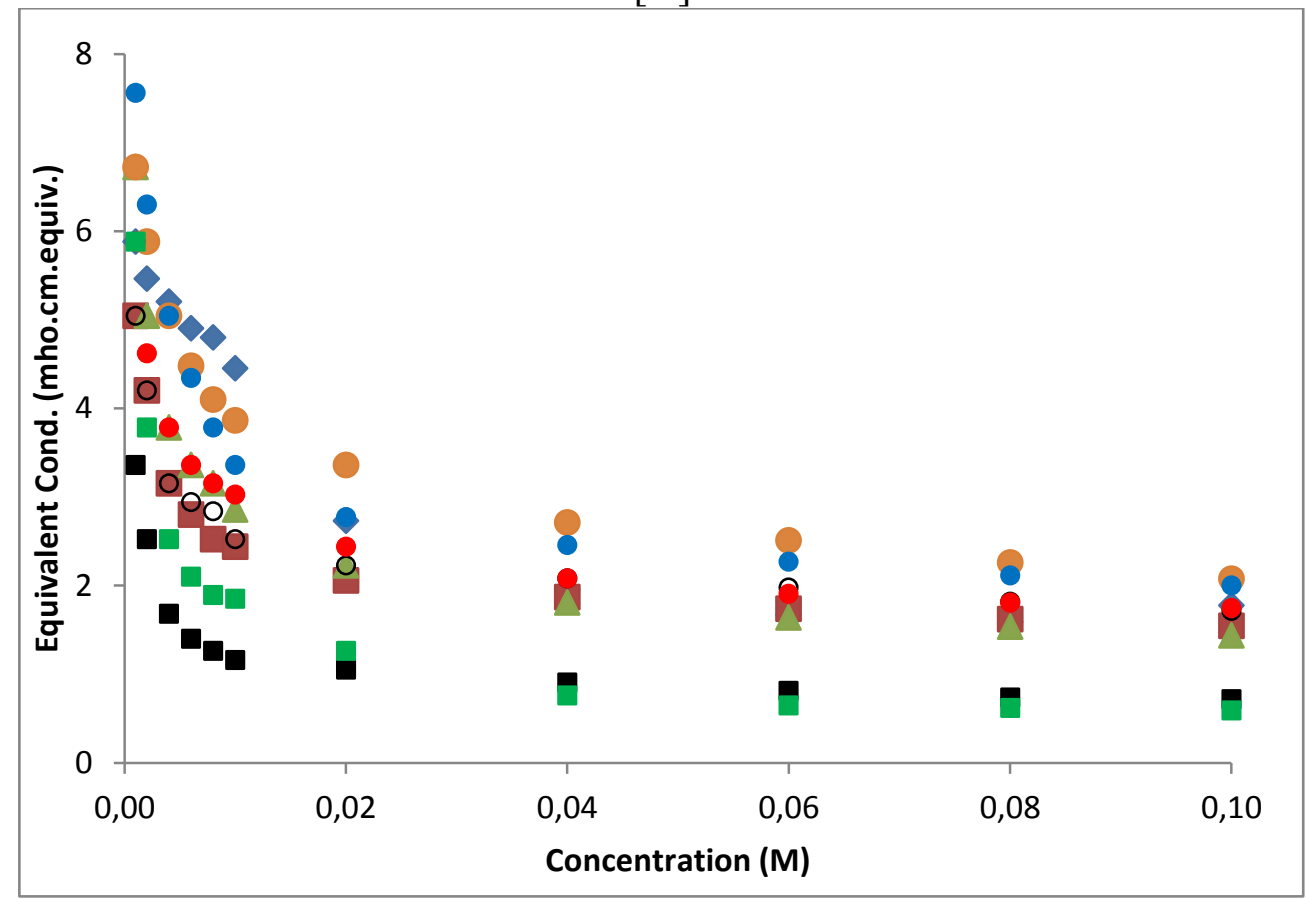

[B]

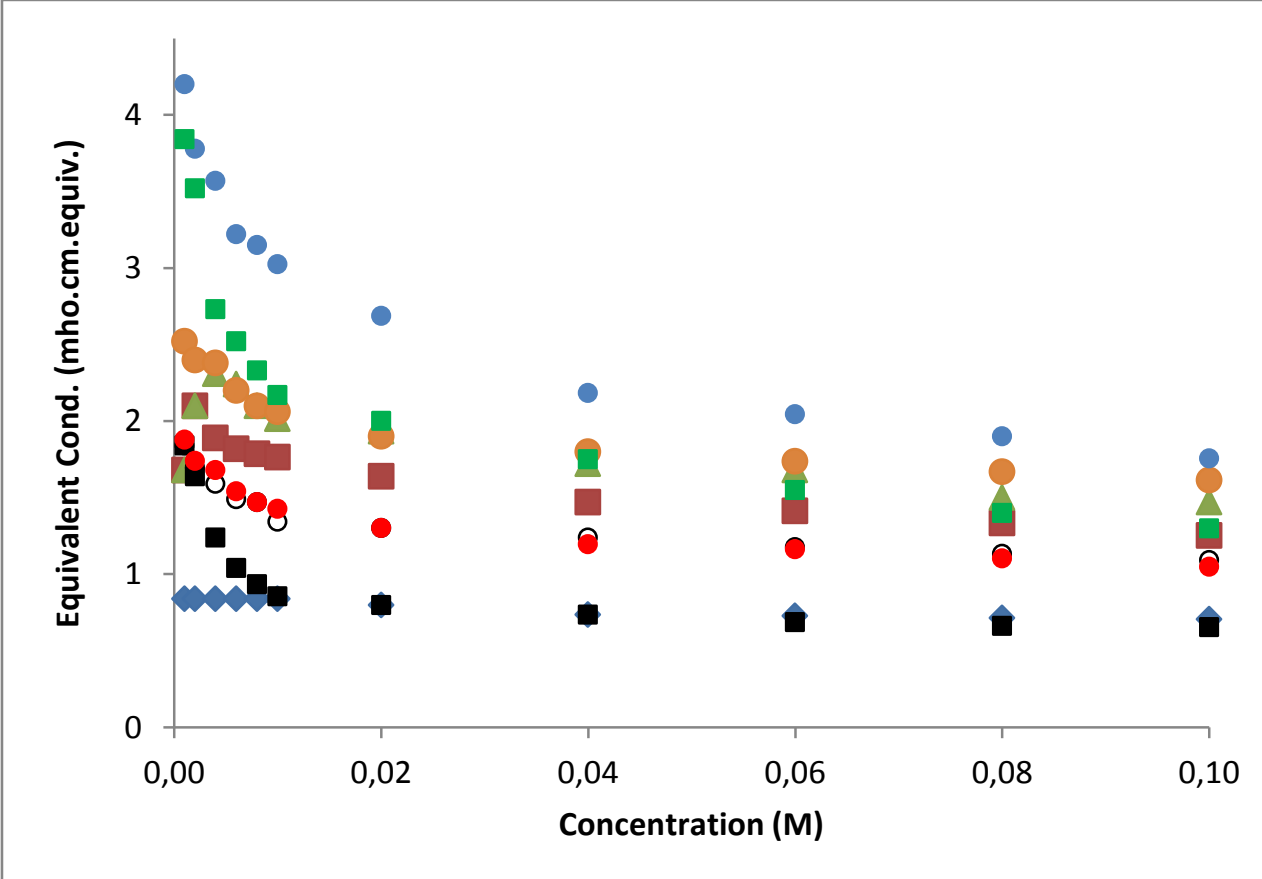

Figure 2: The equivalent conductance $\left(\lambda_{\mathrm{C}}\right)$ verses $\sqrt{c}_{\mathrm{c}}$ of compounds in [A] DMF and [B] DMSO.

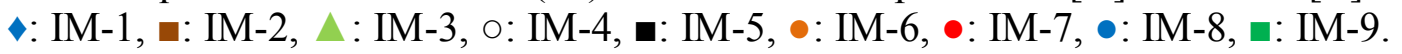

\section{CONDUCTANCE}

The measured conductance of all the compounds in DMF and DMSO was corrected by subtracting the conductance of pure solvent and are given in Tables 4 and 5 respectively. It is observed that conductance increases with concentration for both the solvents. Further, conductance is higher in DMF than that in DMSO.

From these conductance values, equivalent conductance was calculated which are shown in Figure 2. It is obvious from these figures that for all the compounds behave as weak electrolytes in DMF and equivalent conductance increases uninterruptedly with decreasing concentration for all the compounds in DMF and DMSO. 


\section{Acknowledgment}

Authors are thankful to Head of Chemistry Department, Saurashtra University, Rajkot, India for providing necessary facilities.

\section{References}

[1] C. Hu, X. Li, W. Wang, L. Zhang, L. Tao, X. Dong, R. Sheng, B. Yang, Y. Hu, Bioorg. Med. Chem.19, 2011, 5454-5461

[2] P. Mc Cormark, P. Jones, S. Rowland, J. Rapid Comm. Mass Spectro.,16(7) ,705-712 (2002).

[3] N. Venteclef, R. Guilard, Issadou, Marc. Bio. Chem. Pharma. 69 (7), 1041-1048 (2005).

[4] G. Rima, J. Satge, H. Santenac-Roumanou, M. Fatome, G. Lion, I. D. Laval, Eur. J. Med. Chem., 28(10), 761-767 (1993).

[5] G. Le Bihan, F. Rondu, A. Pelé-Tounian, X. Wang, S. Lidy, E. Touboul, A. Lamouri, G. Dive, J. Huet, B. Pfeiffer, P. Renard, B. Guardiola-Lemaître, D. Manéchez, L. Pénicaud, A. Ktorza, J. J. J. Med. Chem. 42(9),1587-603 (1999).

[6] S. Regunathan, D. L. Feinstein, D. J. Reis, Ann. New York Acad. Sci., 881, 410-419, (1999).

[7] N. G. Morgan, Chan, L. F. Sue, Curr. Pharma. Design, 7(14), 1413-1431 (2001).

[8] X. Guan, Y. Hu, Expert Opin Ther Pat. 22(11):1353-65 (2012).

[9] V. Jovancicevic, J. Yang, PCT/US2008/087600-2009

[10] L. B. Volodarsky, Imidazoline Nitroxides: Applications- - CRC Press, Mar 31, 1988.

[11] J. A. Riddick, W. B, Bunger, T. Sakano, Organic Solvents-Physical Properties and Methods of Purification, Techniques of Chemistry, Vol II, Wiley-Interscience Publication, John Wiley, New York, 1989, Fourth edition.,

[12] G. L. Slonimskii, A. A. Askadshii, A. I. Kitaigorodskii, Vysokomol, Soyed, 12A, 494 (1970).

[13]H. A. Lorentz and Lorentz, “Theory of Electronics”, Leipzig 1906. 